\title{
Effect of Cu Substitution on Thermoelectric Properties of Ge Clathrates
}

\author{
Masahiro Hokazono*, Hiroaki Anno ${ }^{1,2}$ and Kakuei Matsubara ${ }^{2}$ \\ ${ }^{1}$ Department of Materials Science and Electronics, Graduate School of Science and Engineering, \\ Tokyo University of Science, Yamaguchi, Sanyo Onoda 756-0884, Japan \\ ${ }^{2}$ Department of Electronics and Computer Science, Faculty of Science and Engineering, \\ Tokyo University of Science, Yamaguchi, Sanyo Onoda 756-0884, Japan
}

We have prepared polycrystalline $n$-type $\mathrm{Ba}_{8} \mathrm{Cu}_{x} \mathrm{Ga}_{y} \mathrm{Ge}_{46-x-y}(x=0-5, y=16-3 x)$ clathrate compounds by arc melting and spark plasma sintering techniques and investigated the effect of $\mathrm{Cu}$ substitution for $\mathrm{Ge}$ on their thermoelectric properties. The Hall carrier concentration for $\mathrm{Cu}$-substituted compounds is almost constant at the order of $10^{20} \mathrm{~cm}^{-3}$, which is comparable to that for $\mathrm{Ba}_{8} \mathrm{Ga}_{16} \mathrm{Ge}_{30}$ stoichiometric compounds. The Seebeck coefficient for these compounds is comparable to that for $n$ - $\mathrm{Ba}_{8} \mathrm{Ga}_{y} \mathrm{Ge}_{46-y}$ compounds. From the analysis of the properties, the effective mass of the conduction band is estimated to be about $1.4 m_{0}$, which is equivalent to or slightly smaller than that of $n-\mathrm{Ba}_{8} \mathrm{Ga}_{y} \mathrm{Ge}_{46-y}$ compounds. The Hall mobility increases as the Cu composition increases. Its temperature dependence obeys approximately $T^{-1 / 2}$ dependence in the range of 80-300 K, indicating the dominance of the alloy disorder scattering. Two models are discussed to account for the reduction in the alloy disorder scattering by $\mathrm{Cu}$ substitution.

(Received October 26, 2004; Accepted January 10, 2005; Published July 15, 2005)

Keywords: clathrate, germanium, copper substitution, thermoelectric properties, Seebeck coefficient, electrical conductivity, effective mass, Hall mobility, relaxation time, alloy disorder scattering

\section{Introduction}

Semiconducting clathrate compounds with a general formula $\mathrm{M}_{8} \mathrm{X}_{46}(\mathrm{M}=\mathrm{Sr}, \mathrm{Ba} ; \mathrm{X}=\mathrm{Si}, \mathrm{Ge}, \mathrm{Sn})$ have been extensively studied as promising candidates for thermoelectric applications because they combine glasslike thermal conductivity and relatively good electronic transport properties. ${ }^{1-8)}$ The unit cell of type-I clathrates contains two pentagonal dodecahedra and six hexakaidecahedra formed by $\mathrm{X}$ atoms, which are fully disordered on the three distinct framework sites. The large cages inside the framework can incorporate alkali-earth atoms and their anharmonic vibration inside the cages reduces the lattice thermal conductivity through an interaction of the guest atoms with a wide spectrum of low frequency phonons. On the other hand, these materials maintain relatively good electronic conduction through the covalent $s p^{3}$ hybridized framework, which dominates the band structure and electronic transport properties of the compounds.

Cordier and Woll ${ }^{9)}$ reported the synthesis of some of transition-metal intermetallic compounds based on $\mathrm{Ba}_{8} \mathrm{Si}_{46}$ and $\mathrm{Ba}_{8} \mathrm{Ge}_{46}$ clathrates. In these compounds, $\mathrm{Si}$ or $\mathrm{Ge}$ atoms at the crystallographic $6 \mathrm{c}$ sites are replaced by transition metals. Recently, we have reported the effects of substitution of transition metals $\left(\mathrm{Pt}^{10)}\right.$ and $\left.\mathrm{Pd}^{11)}\right)$ for $\mathrm{Ge}$ on the electronic and thermoelectric properties of $\mathrm{Ba}_{8} \mathrm{Ga}_{16} \mathrm{Ge}_{30}$-based compounds. The important points obtained from the study are as follows. In these compounds, the transition metals preferentially occupy at the crystallographic $6 \mathrm{c}$ sites, and the Seebeck coefficient is greatly enhanced by substitution of these transition metals. Furthermore, $p$-type clathrate compounds with varying carrier concentrations can be successfully prepared by Pd substitution.

To improve the thermoelectric figure of merit by this transition metal substitution, we have systematically inves- tigated the thermoelectric properties of transition-metalsubstituted Ge and Si clathrate compounds. In this paper, we report an investigation of the electronic and thermoelectric properties of polycrystalline $\mathrm{Ba}_{8} \mathrm{Cu}_{x} \mathrm{Ga}_{y} \mathrm{Ge}_{46-x-y}(x=0-5$, $y=16-3 x$ ) compounds with varying $\mathrm{Cu}$ compositions in an effort to elucidate the effect of transition metal substitution in Ge clathrate compounds.

\section{Experimental Details}

Polycrystalline $\mathrm{Ba}_{8} \mathrm{Cu}_{x} \mathrm{Ga}_{y} \mathrm{Ge}_{46-x-y} \quad(x=0-5, y=16-$ $3 x$ ) compounds were prepared by using arc melting and spark plasma sintering techniques. The composition ( $x$ and $y=$ $16-3 x$ ) of the compounds was settled by considering the charge compensation for $\mathrm{Ba}^{2+}$ ions by substituting $\mathrm{Cu}$ and $\mathrm{Ga}$ : $\mathrm{Cu}$ nominally acts as a "trivalent" acceptor and $\mathrm{Ga}$ acts as a "monovalent" acceptor. Ba ingot $(3 \mathrm{~N}), \mathrm{Cu}$ grain $(4 \mathrm{~N})$, Ga ingot $(6 \mathrm{~N})$, and Ge ingot (4N) were used as the starting materials. $\mathrm{Ba}_{8} \mathrm{Cu}_{x} \mathrm{Ga}_{y} \mathrm{Ge}_{46-x-y}$ ingots were first prepared by arc melting constituent elements in an argon atmosphere. The obtained ingots were ground to fine powder $(<90 \mu \mathrm{m})$ and sintered at $988-1088 \mathrm{~K}$ and $30 \mathrm{MPa}$ for $60 \mathrm{~min}$ in an argon atmosphere by the spark plasma sintering method. The density of each sample was measured by the Archimedes technique. Powder X-ray diffraction (XRD) and electron probe microanalysis (EPMA) of polished surface of samples were employed to check the crystal structure and the chemical composition of samples.

The electrical conductivity $\sigma$ and the Seebeck coefficient $S$ were measured in the temperature range of 300-900 K. Hall measurements were performed in the temperature range of $80-300 \mathrm{~K}$ by applying an external magnetic field of $1 \mathrm{~T}$ using the van der Pauw's method. The Hall mobility $\mu$ was determined from the electrical conductivity $\sigma$ and the Hall coefficient $R_{\mathrm{H}}$ using $\mu=\sigma R_{\mathrm{H}}$. 


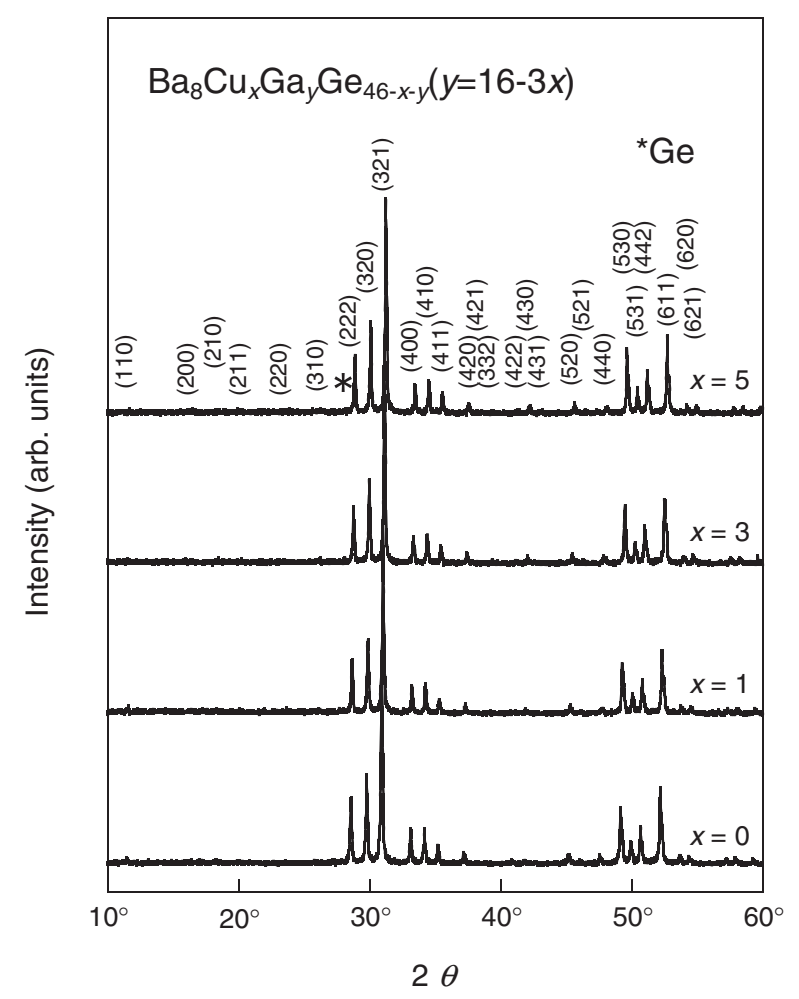

Fig. 1 X-ray diffraction patterns of $\mathrm{Ba}_{8} \mathrm{Cu}_{x} \mathrm{Ga}_{y} \mathrm{Ge}_{46-x-y} \quad(y=16-3 x)$ compounds with $x=0,1,3$, and 5 .

\section{Results and Discussion}

Figure 1 shows $\mathrm{X}$-ray diffraction patterns for $\mathrm{Ba}_{8} \mathrm{Cu}_{x^{-}}$ $\mathrm{Ga}_{y} \mathrm{Ge}_{46-x-y}(x=0,1,3$, and $5 ; y=16-3 x)$ compounds. The X-ray diffraction patterns of all samples were indexed to a cubic unit cell corresponding to the clathrate structure (Cubic, space group $P m \overline{3} n$ ). Although a weak diffraction peak due to unreacted $\mathrm{Ge}$ phase was observed for the $\mathrm{Cu}$ composition $x=5$, the samples with $x=0-4$ were found to be single phase materials.

Table 1 summarizes some room-temperature properties for $\mathrm{Ba}_{8} \mathrm{Cu}_{x} \mathrm{Ga}_{y} \mathrm{Ge}_{46-x-y}(x=0-5 ; y=16-3 x)$ compounds. EPMA confirmed the homogeneity of the samples with $x=$ $0-4$ and the existence of a trace amount of unreacted Ge phase in the sample with $x=5$. As shown in Table 1, it was also found from EPMA that the samples had almost the same compositions as the nominal ones that expected from the amounts of constituent elements in the starting mixtures. The analysis of XRD data showed that the lattice constant decreased linearly as the $\mathrm{Cu}$ composition $x$ increased, indicating the substitution of $\mathrm{Cu}$ for $\mathrm{Ge}$ sites. The extrapolation to $x=6$ from the experimental dependence agrees well with the value $\left(1.06859 \mathrm{~nm}^{9}\right)$ for $\mathrm{Ba}_{8} \mathrm{Cu}_{6} \mathrm{Ge}_{40}$. This change of the lattice constant can be explained in terms of the Vegard's law. The Hall coefficient for all samples was found to be negative and almost independent of the temperature between $80-300 \mathrm{~K}$, indicating dominant $n$-type conduction in nearly degenerate range. The Hall carrier concentration at room temperature of the samples was nearly constant at the order of $10^{20} \mathrm{~cm}^{-3}$. Due to the charge compensation for $\mathrm{Ba}$ ions, the carrier concentration for $\mathrm{Cu}$-substituted samples is comparable to that for the $\mathrm{Ba}_{8} \mathrm{Ga}_{16} \mathrm{Ge}_{30}$ stoichiometric compound.

Since the thermoelectric properties depend strongly on the carrier concentration, we need to isolate the effect of $\mathrm{Cu}$ substitution from the carrier concentration dependence of the samples with slightly different carrier concentrations. Thus, we compared the carrier concentration dependence of the room temperature electrical conductivity and Seebeck coefficient for $\mathrm{Ba}_{8} \mathrm{Cu}_{x} \mathrm{Ga}_{y} \mathrm{Ge}_{46-x-y} \quad(x=1-5, \quad y=16-3 x)$ compounds to that for $\mathrm{Ba}_{8} \mathrm{Ga}_{y} \mathrm{Ge}_{46-y}$ compounds, ${ }^{8)}$ as shown in Figs. 2 and 3, respectively. It is evident from Fig. 2 that the electrical conductivity $\sigma$ is significantly enhanced by $\mathrm{Cu}$ substitution at similar carrier concentration as compared to $n$ $\mathrm{Ba}_{8} \mathrm{Ga}_{y} \mathrm{Ge}_{46-y}$ compounds. On the other hand, the Seebeck coefficient for $\mathrm{Ba}_{8} \mathrm{Cu}_{x} \mathrm{Ga}_{y} \mathrm{Ge}_{46-x-y}(x=1-5, y=16-3 x)$ compounds is comparable to or slightly smaller than that for $n$ - $\mathrm{Ba}_{8} \mathrm{Ga}_{y} \mathrm{Ge}_{46-y}$ compounds. We estimated the effective mass assuming a single parabolic band model with alloy disorder scattering as dominant scattering mechanism, as will be discussed later. We first calculated the reduced Fermi energy $\eta$ from the experimental Seebeck coefficient data using

$$
S=-\frac{k_{\mathrm{B}}}{e}\left[\frac{2 F_{1}(\eta)}{F_{0}(\eta)}-\eta\right]
$$

where $k_{\mathrm{B}}$ is Boltzman's constant, $e$ is electron charge and $F_{x}$ is a Fermi integral of order $x$. The carrier concentration $n$ can be expressed as

$$
n=4 \pi\left(\frac{2 m^{*} k_{\mathrm{B}} T}{h^{2}}\right)^{\frac{3}{2}} F_{\frac{1}{2}}(\eta),
$$

where $m^{*}$ is the effective mass, $T$ is the temperature, and $h$ is Plank's constant. Thus, the effective mass was calculated by using the calculated $\eta$ and the experimental carrier concen-

Table 1 Some room-temperature properties for $\mathrm{Ba}_{8} \mathrm{Cu}_{x} \mathrm{Ga}_{y} \mathrm{Ge}_{46-x-y}(x=0-5, y=16-3 x)$ compounds.

\begin{tabular}{ccccc}
\hline$x$ & $\begin{array}{c}\text { Nominal } \\
\text { composition }\end{array}$ & EPMA composition & $\begin{array}{c}\text { Density, } \\
D / \mathrm{g} \mathrm{cm}^{-3}\end{array}$ & $\begin{array}{c}\text { Lattice constant, } \\
a_{0} / \mathrm{nm}\end{array}$ \\
\hline 0 & $\mathrm{Ba}_{8} \mathrm{Ga}_{16} \mathrm{Ge}_{30}$ & $\mathrm{Ba}_{7.68} \mathrm{Ga}_{16.87} \mathrm{Ge}_{29.45}$ & $5.782(99.5 \%)$ & $\begin{array}{c}\text { Carrier concentration, } \\
n / 10^{20} \mathrm{~cm}{ }^{-3}\end{array}$ \\
1 & $\mathrm{Ba}_{8} \mathrm{Cu}_{1} \mathrm{Ga}_{13} \mathrm{Ge}_{32}$ & $\mathrm{Ba}_{8.15} \mathrm{Cu}_{0.94} \mathrm{Ga}_{13.49} \mathrm{Ge}_{31.42}$ & $5.792(99.1 \%)$ & $1.07874 \pm 0.00024$ \\
2 & $\mathrm{Ba}_{8} \mathrm{Cu}_{2} \mathrm{Ga}_{10} \mathrm{Ge}_{34}$ & $\mathrm{Ba}_{8.01} \mathrm{Cu}_{1.93} \mathrm{Ga}_{10.23} \mathrm{Ge}_{33.83}$ & $5.844(99.6 \%)$ & $1.07529 \pm 0.00018$ \\
3 & $\mathrm{Ba}_{8} \mathrm{Cu}_{3} \mathrm{Ga}_{7} \mathrm{Ge}_{36}$ & $\mathrm{Ba}_{8.12} \mathrm{Cu}_{3.05} \mathrm{Ga}_{7.19} \mathrm{Ge}_{35.64}$ & $5.859(99.3 \%)$ & $1.07312 \pm 0.00016$ \\
4 & $\mathrm{Ba}_{8} \mathrm{Cu}_{4} \mathrm{Ga}_{4} \mathrm{Ge}_{38}$ & $\mathrm{Ba}_{8.11} \mathrm{Cu}_{4.12} \mathrm{Ga}_{4.06} \mathrm{Ge}_{37.71}$ & $5.921(99.8 \%)$ & $1.07122 \pm 0.00020$ \\
5 & $\mathrm{Ba}_{8} \mathrm{Cu}_{5} \mathrm{Ga}_{1} \mathrm{Ge}_{40}$ & $\mathrm{Ba}_{8.08} \mathrm{Cu}_{5.25} \mathrm{Ga}_{1.00} \mathrm{Ge}_{39.67}$ & $5.820(97.7 \%)$ & $1.06957 \pm 0.00014$ \\
\hline
\end{tabular}




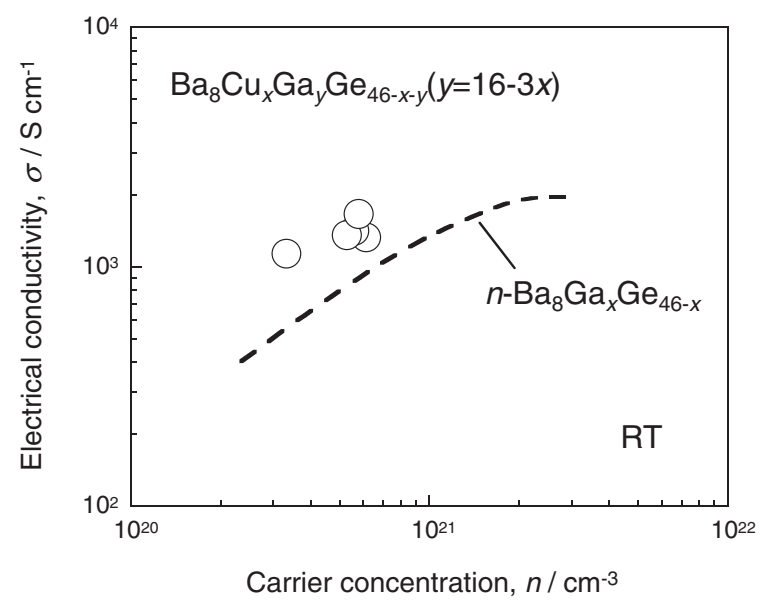

Fig. 2 Electrical conductivity $\sigma$ at room temperature as a function of carrier concentration $n$ for $\mathrm{Ba}_{8} \mathrm{Cu}_{x} \mathrm{Ga}_{y} \mathrm{Ge}_{46-x-y}(x=1-5, y=16-3 x)$ compounds.

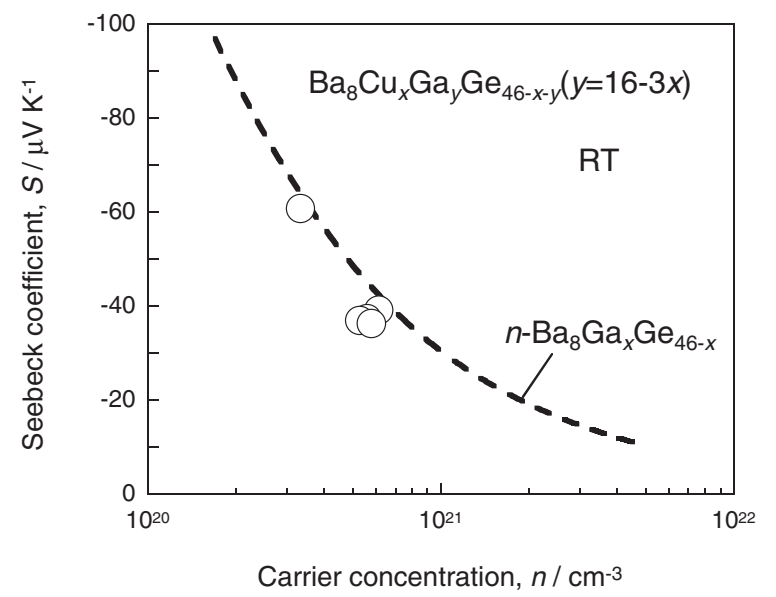

Fig. 3 Seebeck coefficient $S$ at room temperature as a function of carrier concentration $n$ for $\mathrm{Ba}_{8} \mathrm{Cu}_{x} \mathrm{Ga}_{y} \mathrm{Ge}_{46-x-y}(x=1-5, y=16-3 x)$ compounds.

tration data $n$. The resulting effective mass $m^{*}$ at room temperature is $1.4 m_{0}$, where $m_{0}$ is the electron mass, for $\mathrm{Ba}_{8} \mathrm{Cu}_{x} \mathrm{Ga}_{y} \mathrm{Ge}_{46-x-y} \quad(x=1-5, \quad y=16-3 x)$ compounds. This value is equivalent to or slightly smaller than that of $\mathrm{Ba}_{8} \mathrm{Ga}_{x} \mathrm{Ge}_{46-x}$ compounds $\left(m^{*}=1.5 m_{0}\right)$. According to the calculation of the electronic band structure of transitionmetal clathrate $\left(\mathrm{Ba}_{8} \mathrm{X}_{6} \mathrm{Si}_{40}\right.$ and $\mathrm{Ba}_{8} \mathrm{X}_{6} \mathrm{Ge}_{40}: \mathrm{X}=\mathrm{Cu}, \mathrm{Ag}$, and $\mathrm{Au})$ by Akai et al., ${ }^{12,13)}$ the valence and conduction bands near the Fermi level are essentially derived from $s p^{3}$ bonding nature of the framework. The calculation also shows that the effective mass of the conduction band edge for $\mathrm{X}=\mathrm{Cu}$ is slightly smaller than that of $\mathrm{Ba}_{8} \mathrm{Ga}_{16} \mathrm{Ge}_{30},{ }^{13)}$ in good agreement with our experimental result.

The transport properties in semiconductors are determined by the band structure and various scattering mechanisms. To elucidate the origin of the enhancement in the electrical conductivity, we investigated the carrier mobility and the scattering mechanism of $\mathrm{Ba}_{8} \mathrm{Cu}_{x} \mathrm{Ga}_{y} \mathrm{Ge}_{46-x-y} \quad(x=0-5$, $y=16-3 x$ ) compounds. Figure 4 shows the Hall mobility

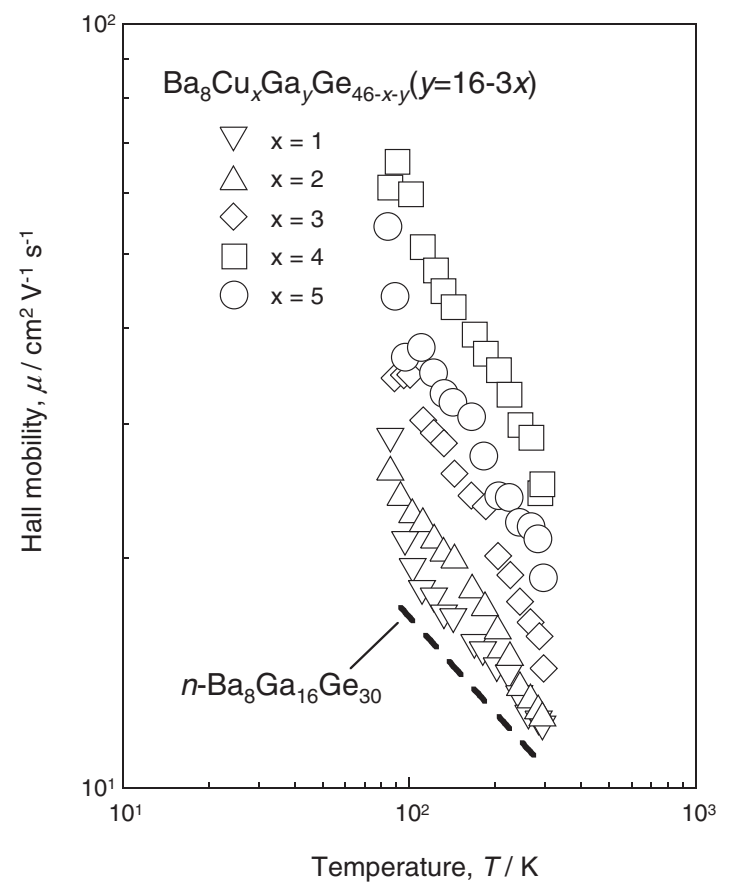

Fig. 4 Hall mobility $\mu$ as a function of temperature for $\mathrm{Ba}_{8} \mathrm{Cu}_{x^{-}}$ $\mathrm{Ga}_{y} \mathrm{Ge}_{46-x-y}(x=0-5, y=16-3 x)$ compounds.

as a function of temperature for $\mathrm{Ba}_{8} \mathrm{Cu}_{x} \mathrm{Ga}_{y} \mathrm{Ge}_{46-x-y}$ ( $x=$ $0-5, y=16-3 x$ ) compounds. The Hall mobility for $\mathrm{Ba}_{8}-$ $\mathrm{Cu}_{x} \mathrm{Ga}_{y} \mathrm{Ge}_{46-x-y}(x=0-5, y=16-3 x)$ compounds obeys approximately $\mu \propto T^{-1 / 2}$ behavior in the temperature range of $80-300 \mathrm{~K}$, indicating that the alloy disorder scattering is the dominant scattering mechanism. Furthermore, it is interesting to note that the Hall mobility tends to increase with increasing $\mathrm{Cu}$ composition $x$. The enhancement of Hall mobility is also clearly identified from Fig. 5, which shows the $\mathrm{Cu}$ composition dependence of the room temperature Hall mobility for $\mathrm{Ba}_{8} \mathrm{Cu}_{x} \mathrm{Ga}_{y} \mathrm{Ge}_{46-x-y} \quad(x=0-5, \quad y=16-3 x)$ compounds. The Hall mobility values for samples with high $\mathrm{Cu}$ compositions $(x=4,5)$ are about two times larger than that for the $\mathrm{Ba}_{8} \mathrm{Ga}_{16} \mathrm{Ge}_{30}(x=0)$ sample. Since the carrier concentration for $\mathrm{Ba}_{8} \mathrm{Cu}_{x} \mathrm{Ga}_{y} \mathrm{Ge}_{46-x-y}(x=1-5, y=16-$ $3 x$ ) compounds is nearly equivalent to that for $\mathrm{Ba}_{8} \mathrm{Ga}_{16} \mathrm{Ge}_{30}$ $(x=0)$ compounds, the observed enhancement of the electrical conductivity $\sigma$ is attributed mainly to the increased Hall mobility.

We finally discuss possible models to account for the observed reduction of alloy disorder scattering by $\mathrm{Cu}$ substitution for $\mathrm{Ba}_{8} \mathrm{Cu}_{x} \mathrm{Ga}_{y} \mathrm{Ge}_{46-x-y}(x=0-5, y=16-3 x)$ compounds. As reported by Cordier and Woll, ${ }^{9)}$ one of important crystallographic features in transition-metal clathrate compounds, including $\mathrm{Ba}_{8} \mathrm{Cu}_{6} \mathrm{Ge}_{40}$ and $\mathrm{Ba}_{8} \mathrm{Cu}_{4} \mathrm{Si}_{42}$, is the preferential occupation of transition metal atoms at the $6 \mathrm{c}$ sites. This feature was also observed for a series of $\mathrm{Ba}_{8} \mathrm{X}_{x} \mathrm{Ga}_{y} \mathrm{Ge}_{46-x-y}$ compounds with $\mathrm{X}=\mathrm{Pd}, \mathrm{Pt}, \mathrm{Ag}$, and $\mathrm{Au}{ }^{10,14)}$ Similarly, if the $\mathrm{Cu}$ atoms preferentially occupy at the $6 \mathrm{c}$ site, the scattering of carriers may decrease due to the local ordering in the framework of the clathrate structure, which determines the electronic transport properties.

Since the Ga composition decreases when the $\mathrm{Cu}$ composition increases, the total amount of atoms $(x+y=16-2 x)$ 


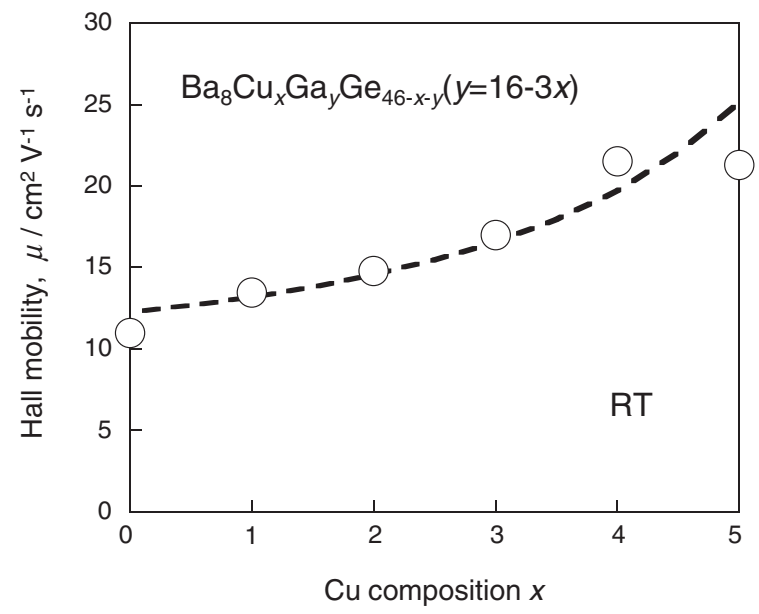

Fig. 5 Hall mobility $\mu$ at room temperature as a function of $\mathrm{Cu}$ composition $x$ for $\mathrm{Ba}_{8} \mathrm{Cu}_{x} \mathrm{Ga}_{y} \mathrm{Ge}_{46-x-y}(x=0-5, y=16-3 x)$ compounds. The dashed line is a fit of the experimental data to an alloy disorder scattering model.

substituted for Ge decreases, resulting in the decrease in alloy disorder scattering. In this model, the electron mobility $\mu_{\mathrm{A}}$ can be expressed by Brook's formula: ${ }^{15)}$

$$
\mu_{\mathrm{A}}=\frac{\sqrt{2 \pi} e \hbar^{4} N_{0}}{3 \alpha(1-\alpha) m^{* 5 / 2}} \frac{1}{(\Delta E)^{2} \sqrt{\kappa_{\mathrm{B}} T}},
$$

where $N_{0}$ is the number of atoms per unit volume, $m^{*}$ is a band-edge effective mass, $\alpha$ is the fractional concentration of one of the species, and $\Delta E$ is an energy parameter characterizing the alloy potential fluctuations. $\mathrm{Ba}_{8} \mathrm{Cu}_{x} \mathrm{Ga}_{y} \mathrm{Ge}_{46-x-y}$ $(x=0-5, y=16-3 x)$ compound can be described as an alloy between $\left[\mathrm{Ba}_{8} \mathrm{Ge}_{46}\right]_{\alpha}$ and $\left[\mathrm{Ba}_{8}(\mathrm{CuGa})_{46}\right]_{1-\alpha}$. The dashed line in Fig. 5 is a fit of the experimental data to the alloy disorder scattering model by Eq. (3) with $m^{*}=1.4 m_{0}$ and $\Delta E=0.92 \mathrm{eV}$. In $\mathrm{Si}_{1-x} \mathrm{Ge}_{x}$ alloy, the energy parameters $\Delta E=\sim 0.5 \mathrm{eV}$ and $\sim 0.6 \mathrm{eV}$ have been reported based on this model. ${ }^{15)}$ As seen in Fig. 5, the composition dependence of the Hall mobility can be explained well in terms of alloy disorder scattering model. The relatively large disagreement for $x=5$ may be due to the influence of an impurity (unreacted $\mathrm{Ge}$ ) phase in the sample. We also estimated the relaxation time $\tau$ from the relation $\tau=\mu m^{*} / e$. Figure 6 shows the $\mathrm{Cu}$ composition dependence of the relaxation time $\tau$ at room temperature for $\mathrm{Ba}_{8} \mathrm{Cu}_{x} \mathrm{Ga}_{y} \mathrm{Ge}_{46-x-y} \quad(x=0-5$, $y=16-3 x$ ) compounds. It turns out that the relaxation time $\tau$ increases remarkably with increasing $\mathrm{Cu}$ composition. From these results, it is found that $\mathrm{Cu}$ substitution has a significant effect on the carrier scattering mechanism.

\section{Conclusions}

We have investigated the effect of $\mathrm{Cu}$ substitution for $\mathrm{Ge}$ on the thermoelectric properties of polycrystalline $\mathrm{Ba}_{8} \mathrm{Cu}_{x} \mathrm{Ga}_{y} \mathrm{Ge}_{46-x-y}(x=0-5, y=16-3 x)$ clathrate compounds prepared by arc melting and spark plasma sintering techniques. $\mathrm{Ba}_{8} \mathrm{Cu}_{x} \mathrm{Ga}_{y} \mathrm{Ge}_{46-x-y} \quad(x=1-5, \quad y=16-3 x)$ compounds have nearly degenerate $n$-type conduction, as is the case for $\mathrm{Ba}_{8} \mathrm{Ga}_{16} \mathrm{Ge}_{30}$ stoichiometric compounds. The Hall mobility is significantly enhanced by substituting $\mathrm{Cu}$ for

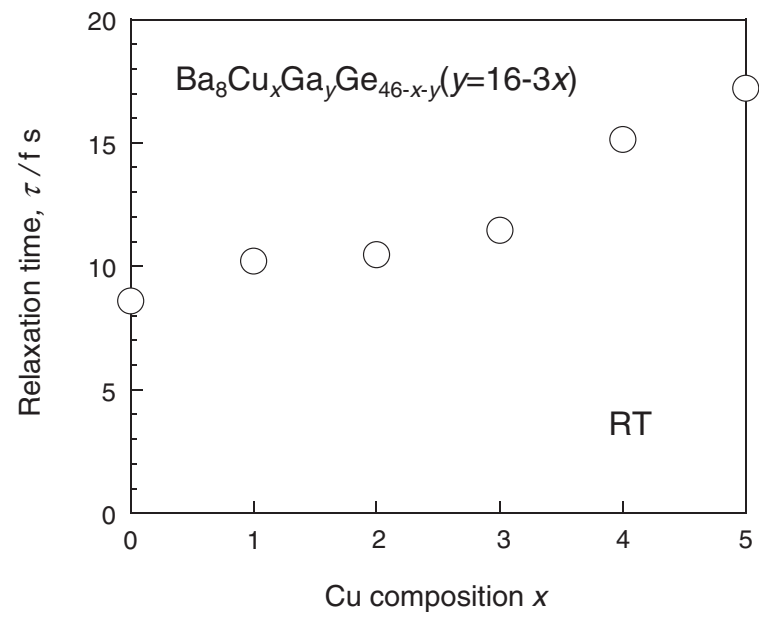

Fig. 6 Relaxation time $\tau$ at room temperature as a function of $\mathrm{Cu}$ composition $x$ for $\mathrm{Ba}_{8} \mathrm{Cu}_{x} \mathrm{Ga}_{y} \mathrm{Ge}_{46-x-y}(x=0-5, y=16-3 x)$ compounds.

Ge while remaining relatively large Seebeck coefficient due to the effective mass of conduction band comparable to or slightly smaller than that for $n-\mathrm{Ba}_{8} \mathrm{Ga}_{y} \mathrm{Ge}_{46-y}$ compounds. The temperature dependence of the Hall mobility indicates that the dominant scattering mechanism of conduction electrons is alloy disorder scattering in the temperature range of $80-300 \mathrm{~K}$. We discussed two models to account for the reduction of carrier scattering by $\mathrm{Cu}$ substitution. One is the effect of local ordering in the framework structure due to the preferential occupation of $\mathrm{Cu}$ at the crystallographic (6c) site. The other is the effect of large decrease in the amount of atoms substituted for $\mathrm{Ge}$ by using $\mathrm{Cu}$ with the valence higher than $\mathrm{Ga}$ for charge compensation for $\mathrm{Ba}$ ions. The observed dependence of Hall mobility on the $\mathrm{Cu}$ composition can be explained in terms of the alloy disorder scattering model considering the later case. Although the clathrate compounds have interesting, favorable physical properties based on a phonon glass and electron crystal concept, the carrier mobility in $n-\mathrm{Ba}_{8} \mathrm{Ga}_{y} \mathrm{Ge}_{46-y}$ compounds is still smaller than that in state-of-the-art thermoelectric materials. Our result, therefore, suggests that the transition metal substitution is an approach to optimize the electronic properties of clathrate compounds for thermoelectric applications.

\section{Acknowledgements}

The authors would like to thank Prof. M. Matsuura and Prof. K. Akai of Yamaguchi University for valuable comments on the electronic structure of clathrate compounds. One of the authors (H.A.) acknowledges the support from the Grant-in-Aid for Young Scientists (B) (KAKENHI No. 16760550) of the Ministry of Education, Culture, Sports, Science and Technology (MEXT) of Japan and the Foundation for Advancement of Science and Technology.

\section{REFERENCES}

1) G. A. Slack: Mat. Res. Soc. Symp. Proc. Vol. 478, eds. by T. M. Tritt, M. G. Kanatzidis, H. B. Lyon, Jr. and G. D. Mahan, (MRS Press, 
Warrendale, Pennsylvania, 1997) pp. 47-54.

2) G. S. Nolas, J. L. Cohn, G. A. Slack and S. B. Schujman: Appl. Phys. Lett. 73 (1998) 178-180.

3) J. L. Cohn, G. S. Nolas, V. Fessatidis, T. H. Metcalf and G. A. Slack: Phys. Rev. Lett. 82 (1999) 779-782.

4) V. L. Kuznetsov, L. A. Kuznetsova, A. E. Kaliazin and D. M. Rowe: J. Appl. Phys. 87 (2000) 7871-7875.

5) G. S. Nolas, T. J. R. Weakly, J. L. Cohn and R. Sharma: Phys. Rev. B. 61 (2000) 3845-3850.

6) G. S. Nolas: Proc. 19th. Int. Conf. on Thermoelectrics, ed. by D. M. Rowe, (BABROW Press, Wales, United Kingdom, 2000) pp. 110-112.

7) G. S. Nolas, J. Sharp and H. J. Goldsmid: Thermoelectrics, (SpringerVerlag, Berlin, 2001) pp. 191-207.

8) H. Anno, M. Hokazono, M. Kawamura, J. Nagao and K. Matsubara: Proc. 21st. Int. Conf. on Thermoelectrics, (IEEE, Piscataway, New
Jersey, 2002) pp. 77-80

9) G. Cordier and P. Woll: J. Less-Common Met. 169 (1991) 291-302.

10) H. Anno, M. Hokazono, M. Kawamura and K. Matsubara: Proc. 22nd. Int. Conf. on Thermoelectrics, (IEEE, Piscataway, New Jersey, 2003) pp. $121-126$.

11) M. Hokazono, M. Kawamura, H. Anno and K. Matsubara: Trans. MRSJ. 29 (2004) 2793-2796.

12) K. Akai, K. Koga, K. Oshiro and M. Matsuura: Trans. MRS-J. 29 (2004) 3647-3650.

13) M. Matsuura and K. Akai (private communication).

14) H. Anno, M. Hokazono and K. Matsubara: Proc. 23rd. Int. Conf. on Thermoelectrics, (IEEE, Piscataway, New Jersey, 2004) [in press].

15) S. Krishnamurthy, A. Sher and A. Chen: Appl. Phys. Lett. 47 (1985) 160-162. 